\title{
Holoprosencephaly: report of four cases and genotype-phenotype correlations
}

\author{
FRANCESCA LAMI $^{1 \dagger}$, DIANA CARLI ${ }^{2 \dagger}$, PAOLA FERRARI $^{1}$, MONICA MARINI $^{3}$, VIOLA ALESI $^{4}$, \\ LORENZO IUGHETTI ${ }^{1}$ and ANTONIO PERCESEPE ${ }^{2 *}$ \\ ${ }^{1}$ Pediatrics Unit, and ${ }^{2}$ Medical Genetics Units, Department of Mother and Child, University of Modena, Via del Pozzo 71, \\ 41124 Modena, Italy \\ ${ }^{3}$ Laboratory of Molecular Genetics, Department of Pediatrics and CEBR, University of Genova, Largo G. Gaslini 5, \\ 16147 Genova, Italy \\ ${ }^{4}$ Medical Genetics Unit, S. Pietro Fatebenefratelli Hospital, Via Cassia 600, 00189 Rome, Italy
}

[Lami F., Carli D., Ferrari P., Marini M., Alesi V., Iughetti L. and Percesepe A. 2013 Holoprosencephaly: report of four cases and genotypephenotype correlations. J. Genet. 92, 97-101]

\section{Introduction}

Holoprosencephaly (HPE) is a heterogeneous disorder with variable expressivity and reduced penetrance. The causes vary from environmental factors to pure genetic forms, namely chromosomal and genomic abnormalities in up to $70 \%$ of the cases, and heterozygous mutations in at least four major genes in 17\% of cases (Dubourg et al. 2004; Solomon et al. 2011). Haploinsufficiency of the sonic hedgehog (SHH) (MIM: 600725) gene represents the most frequent cause, either by loss-of-function gene mutations, or by $7 \mathrm{q} 36$ genomic deletions. In those latter cases genotype/phenotype correlations are complicated by the contiguous presence of a homeobox gene, $H L X B 9$, located $1.2 \mathrm{Mb}$ telomeric to $S H H$, involved in the Currarino syndrome, which is characterized by malformations of structures derived from the caudal region of the embryo (Lynch et al. 2000). Moreover, Currarino syndrome exhibits variable expressivity and reduced penetrance. In the present study we report four cases of HPE, three postnatal and one prenatal, displaying different genetic alterations (a novel SHH point mutation and three genomic deletions involving 7q36 chromosomal region) and different clinical features. In the case of $\mathrm{SHH}$ point mutation, a 'pure' HPE phenotype was found, whereas a more complex syndrome, with associated vertebral, renal, genital, cardiac abnormalities, was observed in the cases with $7 \mathrm{q} 36$ terminal deletion. We describe rare clinical findings, like craniovertebral hinge dysplasia, Hirschsprung's disease and syringomyelia as part of the Currarino syndrome spectrum.

\footnotetext{
*For correspondence. E-mail: percesepe.antonio@unimo.it.

$\dagger$ Francesca Lami and Diana Carli contributed equally to this work.
}

\section{Patients and methods}

\section{Case 1}

T.R., male, was born at term after an uneventful maternal pregnancy during which an ultrasonographic diagnosis of left microphtalmia was made at 33rd week. He is the first-born without familiarity for congenital anomalies and presented normal auxological parameters at birth (weight $3480 \mathrm{~g}$ (25-50th centile), length $50 \mathrm{~cm}$ (25th centile), head circumference $33 \mathrm{~cm}(5-10$ th centile)). The patient had craniofacial dysmorphisms characterized by bitemporal narrowness, poorly delineated brow ridges, ocular asymmetry, bulbous nose with asymmetrical nostrils, long philtrum, thin lips and a highly arched palate. He showed left microphthalmia, associated with a multilocular infero-retro-bulbar cyst, and coloboma of the optic right nerve; CT scan highlighted hypoplasia of the lower nasal cavity and right choanal stenosis. No other malformations were present in other organs. A solitary median maxillary central incisor was noted in the deciduous teeth. During the follow-up, the patient showed a reduced statural and ponderal growth (height and weight were both under the 3 rd centile in all measurements), with a normal neurologic and intellectual development.

\section{Case 2}

C.G., male, was born at 38 weeks of gestational age from cesarean section performed for an intrauterine growth retardation (IUGR); his auxological parameters at birth were all under the 3 rd centile with microcephaly. The patient showed facial dysmorphisms (high forehead with bitemporal narrowness, hypotelorism with lower epicanthal folds, bulbous nose, long philtrum, arched palate, triangular chin and large

Keywords. holoprosencephaly; Currarino syndrome; 7q36 deletion; SHH gene mutation. 
ears with abnormal helix), patency of the foramen ovale, malformation of L5 vertebral body, presenting a butterfly pattern, monolateral left talipes and undescended left testicle. At one-year clinical follow-up a solitary median maxillary central incisor was observed. Cerebral and spinal cord MRI (magnetic resonance imaging) revealed the presence of syringomyelia (between C4 and D4), associated with abnormalities of the craniovertebral hinge. At the age of two, the patient underwent a surgical correction of Hirschsprung's disease diagnosed by biopsy of rectal mucosa performed for chronic constipation. The neurologic and intellectual development were normal throughout the follow-up.
Case 3

M.S., female, was born at term by caesarean section for breech presentation (length $48 \mathrm{~cm}$, 9th centile, weight $2500 \mathrm{~g}$, 2nd centile). She was first-born of consanguineous parents (first cousins), both of Moroccan origin. She presented premature dental eruption, which started at three months and completed at six months, and a reduced statural growth along the follow-up (always under the 3rd centile). The observed craniofacial dysmorphisms were consisting of a flat occiput, bitemporal narrowness, coarse facial features, downslanting palpebral fissures, hypothelorism, blue sclerae,

Table 1. Phenotypic characteristics of the four patients described in the study.

\begin{tabular}{|c|c|c|c|c|}
\hline & $\begin{array}{l}\text { SHH mutation } \\
\text { c. } 132 \mathrm{C}>\mathrm{A}\end{array}$ & $\begin{array}{c}\text { Del } \\
\text { (7)(q36qter) }\end{array}$ & $\begin{array}{c}\text { Del } \\
\text { (7)(q36.2q36.3) }\end{array}$ & $\begin{array}{c}\text { Del } \\
\text { (7)(q36qter) }\end{array}$ \\
\hline \multicolumn{5}{|l|}{ Cerebral and facial anomalies } \\
\hline Corpus callosum agenesis & & & & $\mathrm{X}$ \\
\hline Interemispheric cyst & & & & $\mathrm{X}$ \\
\hline Cerebellar vermis hypoplasia & & & $\mathrm{X}$ & \\
\hline Mild dilation of ventricles and posterior fossa & & & $\mathrm{X}$ & \\
\hline Microcephaly & & $\mathrm{X}$ & & \\
\hline Coloboma of the optic nerve & $\mathrm{X}$ & & & \\
\hline Choanal stenosis & $\mathrm{X}$ & & & \\
\hline Solitary median maxillary central incisor & $\mathrm{X}$ & $\mathrm{X}$ & $\mathrm{X}$ & \\
\hline Precocious dental eruption (from 3 to 6 months) & & & $\mathrm{X}$ & \\
\hline \multicolumn{5}{|l|}{ Dysmorphisms } \\
\hline Bitemporal narrowness & $\mathrm{X}$ & $\mathrm{X}$ & $\mathrm{X}$ & \\
\hline Hypotelorism & & $\mathrm{X}$ & $\mathrm{X}$ & \\
\hline Microphtalmia & $\mathrm{X}$ & & & \\
\hline Blue sclerae & & & $\mathrm{X}$ & \\
\hline Flattened nasal bridge & & $\mathrm{X}$ & & \\
\hline Bulbous nose & $\mathrm{X}$ & $\mathrm{X}$ & $\mathrm{X}$ & \\
\hline Arched palate & $\mathrm{X}$ & $\mathrm{X}$ & & \\
\hline \multicolumn{5}{|l|}{ Vertebral and spinal cord abnormalities } \\
\hline Syringomyelia (C4-D4) & & $\mathrm{X}$ & & \\
\hline Cranio-vertebral hinge abnormalities & & $\mathrm{X}$ & & \\
\hline Butterfly vertebra (L5) & & $\mathrm{X}$ & & \\
\hline Sacral vertebra cleft $(\mathrm{S} 1)$ & & & $\mathrm{x}$ & \\
\hline Partial agenesis of sacro-coccygeal vertebrae & & & $\mathrm{X}$ & \\
\hline Anterior sacral meningocele & & & $\mathrm{X}$ & \\
\hline \multicolumn{5}{|l|}{ Malformations } \\
\hline Brachydactyly with flat last phalanx & & & $\mathrm{X}$ & \\
\hline Cardiac ventricular septal defect with biventricular aorta & & & & $\mathrm{X}$ \\
\hline Patent foramen ovale & & $\mathrm{X}$ & & \\
\hline Severe dorso-lumbar scoliosis & & & $\mathrm{X}$ & \\
\hline Bilateral flat feet & & & $\mathrm{X}$ & \\
\hline Recurrent dislocation of patella & & & $\mathrm{X}$ & \\
\hline Talipes & & $\mathrm{X}$ & & \\
\hline Single umbilical artery & & & & $\mathrm{X}$ \\
\hline Omphalocele & & & & $\mathrm{X}$ \\
\hline Hirschsprung disease & & $\mathrm{X}$ & & \\
\hline Solitary kidney and adrenal gland & & & & $\mathrm{X}$ \\
\hline Bifid uterus & & & $\mathrm{X}$ & \\
\hline \multicolumn{5}{|l|}{ Growth anomalies } \\
\hline Intrauterine growth retardation (IUGR) & & $\mathrm{X}$ & & $\mathrm{X}$ \\
\hline Poor postnatal height-weight growth & $\mathrm{X}$ & & $\mathrm{X}$ & \\
\hline Precocious puberty & & & $\mathrm{X}$ & \\
\hline
\end{tabular}

Light gray background underlines the features belonging to the HPE phenotype, whereas the dark gray background is for the features of Currarino syndrome. 
bulbous nose, large ears, solitary median maxillary central incisor. Moreover, brachydactyly with flat last phalanx, severe dorsal and lumbar scoliosis, bifid uterus, recurrent dislocation of patella, knee and calcaneal valgus with bilateral flat feet were present. She had precocious puberty at seven years. Cerebral MRI showed hypoplasia of the cerebellar vermis and mild dilatation of the lateral ventricles and of the posterior fossa. Finally, a spinal MRI showed a partial agenesis of sacro-coccygeal vertebrae, sagittal cleft of the first sacral vertebra and a small anterior sacral meningocele. The psychomotor development was normal.

\section{Case 4}

A 20-year-old, primigravida was referred to our prenatal diagnosis unit after finding omphalocele at the ultrasound examination at 12 th week of pregnancy. No family history of congenital malformations or other disorders, no exposure to alcohol, teratogenic agents, irradiation, or infectious diseases were reported. During the ultrasonographic examination at 13 th week, the presence of omphalocele was confirmed. Normal auxological and nuchal translucency (NT) parameters (NT: $1.8 \mathrm{~mm}$; crown-rump length: $68 \mathrm{~mm}$ ) were measured. A chorionic villus sampling (CVS) was performed. Followup ultrasonogram at 16-week gestation displayed IUGR, agenesis of the corpus callosum, interemispheric cyst and an atrioventricular septal defect with conotruncal heart malformation. The pregnancy was terminated at the end of 16th week and the autopsy of the foetus confirmed the agenesis of the corpus callosum, the ventricular septal defect with a biventricular origin of the aorta, omphalocele, a single umbilical artery, and renal malformations (solitary kidney and adrenal gland). The phenotypic features of the four cases are reported in table 1.

\section{Methods}

Institutional review board approval was requested and obtained for this study (protocol no. 177/12). All patients gave their consent for cytogenetic and molecular testing. Karyotype analysis was performed on CVS (case 4) and peripheral blood (cases 2 and 3) preparations with a 400band and a 550-band resolution, respectively, using QFQ and
GTG banding. Fluorescent in situ hybridisation (FISH) analysis was carried out on metaphase spreads using subtelomeric probes for chromosome 7 mapping in the $7 \mathrm{q} 36$ region (Vysis, Abbott Park, USA). Array-comparative genomic hybridization $(\mathrm{CGH})$ analysis was performed using a Human Genome CGH Microarray Kit $4 \times 44 \mathrm{~K}$ (Agilent Technologies, Palo Alto, USA), which is based on 44,000 60-mer oligonucleotide probes spanning the genome with an average spatial resolution of $100 \mathrm{~kb}$. The comparative hybridization analysis was performed using Agilent Technologies G2505B Scanner using normal human male DNA (Promega, Madison, USA) as reference. Mutation analysis of the $\mathrm{SHH}$ gene, mapping on $7 \mathrm{q} 36$ was performed by direct sequencing using dye terminator chemistry. The electrophoresis of the sequencing products was carried out in an Applied Biosystems 3100 DNA sequencer (Applied Biosystems, Warrington, UK).

\section{Results}

The following mutations were found in our four cases of HPE (figure 1): Case 1, nonsense mutation in the $S H H$ gene, consisting of a $\mathrm{C}>\mathrm{A}$ transition occurring at the nucleotide 132, causing a stop codon (TAA) for a tyrosin (TAC) in exon 1 (p.Y44X). The absence of the mutation in both the parents suggested a de novo origin. Case 2, subtelomeric deletion of $7 \mathrm{q} 36 \rightarrow 7 \mathrm{qter}$ diagnosed by FISH analysis. It was not possible to further characterize the deletion. Case 3, subtelomeric deletion of $7 \mathrm{q} 36 \rightarrow 7 \mathrm{qter}$ : the array-CGH analysis showed that the size of the deletion was $5.6 \mathrm{Mb}$, extending from $153.3 \mathrm{Mb}(7 \mathrm{q} 36.2)$ to $158.8 \mathrm{Mb}(7 \mathrm{q} 36.3)$ according to the human reference sequence (human genome version 18). Case 4, Prenatal karyotypic analysis on CVS suggested a subtelomeric deletion of the long arm of chromosome 7. The microdeletion, encompassing the region $7 \mathrm{q} 36 \rightarrow 7 \mathrm{qter}$, was confirmed by FISH analysis with subtelomeric probes and was not further characterized.

\section{Discussion}

The four different cases described in the present study recapitulate the clinical and genetic heterogeneity of HPE.

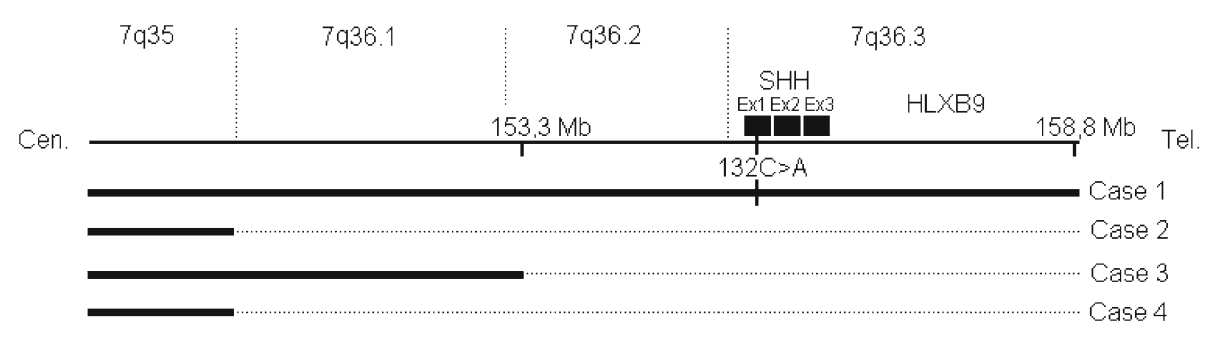

Figure 1. Schematic representation of the mutations reported in the four HPE cases. Solid lines represent the normal chromosome; dotted lines report the deleted genomic segment. For case 1 , the SHH nonsense mutation is reported as a notch on the solid line. For cases 2 and 4, the centromeric breakpoints are presumptive based on the subtelomeric FISH analysis (not characterized by array-CGH). Ex is for exon. 
Case 1, due to the c. $132 \mathrm{C}>\mathrm{A}$, previously undescribed $S H H$ gene mutation, can be included into the microforms of the HPE, characterized by midline defects without the typical HPE-related brain malformations (Dubourg et al. 2007). The presence of a microform is in contrast with the early termination induced by the mutation falling into the highly conserved $\mathrm{N}$-terminal domain, which is crucial for all known signalling activities of the SHH protein (Porter et al. 1995); however, this finding is consistent with the hypothesis that the final phenotypic outcome is determined by the unpredictable interactions of multiple gene products and/or environmental factors (Nanni et al. 1999; Solomon et al. 2012).

Mild phenotypes account for a share varying from 15 to $34 \%$ of the total SHH mutations, which are instead mostly associated with lobar and semilobar phenotypes (Solomon et al. 2010; Mercier et al. 2011). Our patient also shows a choanal stenosis, consistent with the previously described association of the nasal malformations with the microform of HPE in $74 \%$ of the cases (Mercier et al. 2011). The presence of ocular abnormalities (micropthalmia and optic nerve coloboma) in case 1 is accounted for the inactivation through loss-of-function mutations of the inhibitory role of $\mathrm{SHH}$ on PAX6 gene in ocular separation (Macdonald et al. 1995). Case 1 is the only one of the presented HPE cases displaying a coloboma, in accordance with the higher frequency of this malformation in $\mathrm{SHH}$ point mutations than in 7q36 terminal deletions (Horn et al. 2004; Pineda-Alvarez et al. 2011).

Case 2, due to a 7q36 deletion, associates the facial phenotype of HPE with vertebral (craniovertebral hinge dysplasia and L5 butterfly vertebra) and spinal cord (syringomyelia) abnormalities. The vertebral malformations in association with the Hirschsprung's disease can be referred to as Currarino syndrome, in which the Hirschsprung's disease has been described as part of the phenotype in less than 10 cases (Baltogiannis et al. 2003; Volk et al. 2007). Also the craniovertebral hinge abnormality can be ascribed to the Currarino syndrome, confirming the recent first report of an hypoplasia of the odontoid process of the 2 nd cervical vertebra in the syndrome (Zen et al. 2010), consistent with the pattern of embryonic $H L X B 9$ gene expression in the whole spinal cord (Hagan et al. 2000). Syringomyelia of the C4-D4 vertebral tract is a rare finding in HPE/Currarino phenotypes (Turgut et al. 2006): in our case, the absence of an apparent cause (Arnold Chiari malformation or meningocele) supports the definition of idiopathic syringomyelia (Roy et al. 2011), although a disturbance in the cerebrospinal flow can not be excluded.

Case 3, due to a terminal 7q36.2-7q36.3 deletion encompassing both $S H H$ and $H L X B 9$ genes, associate the features of HPE and Currarino triad in a typical phenotype of contiguous gene syndrome, presenting with a lobar form and typical dysmorphisms of HPE and the complete spectrum of the Currarino syndrome (partial sacrococcigeal agenesis, anterior sacral meningocele and bifid uterus). In addition, the patient also presents hand anomalies (brachydactyly with flat last phalanx), a feature that has been described in $45 \%$ of the 7q36 terminal deletions (Frints et al. 1998) and in $16 \%$ of SHH mutations (Mercier et al. 2011).

Case 4, a 16-weeks foetus with a prenatally detected $7 q 36$ terminal deletion, presents incomplete features of HPE (corpus callosus agenesis) and of Currarino syndrome (renal agenesis). Additionally, omphalocele and a severe cardiac malformation (septal and outflow tract) were present. A cardiac malformation has been reported in $14 \%$ of $7 q 36$ terminal deletions and in all those cases the proximal breakpoint was falling centromeric to 7q36 (Frints et al. 1998). Since our proximal breakpoint has not been characterized, it is possible to hypothesize a larger deletion in our case also, explaining as well the presence of the omphalocele, not previously reported in cases with 7q36 deletions (Frints et al. 1998). On the other hand, in case 3 , a minimal terminal deletion of $5.6 \mathrm{Mb}$ was found responsible of a complete expression of HPE and Currarino syndrome with no additional visceral malformations, supporting the exclusive role of $\mathrm{SHH}$ and $H L X B 9$ haploinsufficiency in causing the 7q36 phenotype.

In conclusion, features of Currarino syndrome are frequently found in association with HPE in patients with $7 q 36$ deletions, whereas a 'pure' HPE phenotype is found in the SHH point mutation. In deciding the strategy for testing HPE patients, the presence of associated vertebral, renal, genital, cardiac abnormalities should orient towards a genomic analysis in the suspect of a microdeletion.

\section{References}

Baltogiannis N., Mavridis G., Soutis M. and Keramidas D. 2003 Currarino triad associated with Hirschsprung's disease. J. Pediatr. Surg. 38, 1086-1089.

Dubourg C., Lazaro L., Pasquier L., Bendavid C., Blayau M., Le Duff F. et al. 2004 Molecular screening of SHH, ZIC2, SIX3, and TGIF genes in patients with features of holoprosencephaly spectrum: mutation review and genotype-phenotype correlations. Hum. Mutat. 24, 43-51.

Dubourg C., Bendavid C., Pasquier L., Henry C., Odent S. and David V. 2007 Holoprosencephaly. Orphanet J. Rare Dis. 2 , 8.

Frints S. G., Schoenmakers E. F., Smeets E., Petit P. and Fryns J. P. 1998 De novo 7q36 deletion: breakpoint analysis and types of holoprosencephaly. Am. J. Med. Genet. 75, 153-158.

Hagan D. M., Ross A. J., Strachan T., Lynch S. A., Ruiz-Perez V., Wang Y. M. et al. 2000 Mutation analysis and embryonic expression of the HLXB9 Currarino syndrome gene. Am. J. Hum. Genet. 66, 1504-1515.

Horn D., Tönnies H., Neitzel H., Wahl D., Hinkel G. K., von Moers A. and Bartsch O. 2004 Minimal clinical expression of the holoprosencephaly spectrum and of Currarino syndrome due to different cytogenetic rearrangements deleting the Sonic Hedgehog gene and the HLXB9 gene at 7q36.3. Am. J. Med. Genet. 128, 85-92.

Lynch S. A., Wang Y., Strachan T., Burn J. and Lindsay S. 2000 Autosomal dominant sacral agenesis: Currarino syndrome. $J$. Med. Genet. 37, 561-566.

Macdonald R., Barth K. A., Xu Q., Holder N., Mikkola I. and Wilson S. W. 1995 Midline signalling is required for Pax gene regulation and patterning of the eyes. Development 121, 32673278 . 
Mercier S., Dubourg C., Garcelon N., Campillo-Gimenez B., Gicquel I., Belleguic M. et al. 2011 New findings for phenotypegenotype correlations in a large European series of holoprosencephaly cases. J. Med. Genet. 48, 752-760.

Nanni L., Ming J. E., Bocian M., Steinhaus K., Bianchi D. W., Die-Smulders C. et al. 1999 The mutational spectrum of the sonic hedgehog gene in holoprosencephaly: SHH mutations cause a significant proportion of autosomal dominant holoprosencephaly. Hum. Mol. Genet. 8, 2479-2488.

Pineda-Alvarez D. E., Solomon B. D., Roessler E., Balog J. Z., Hadley D. W., Zein W. M. et al. 2011 A broad range of ophthalmologic anomalies is part of the holoprosencephaly spectrum. Am. J. Med. Genet. 155, 2713-2720.

Porter J. A., von Kessler D. P., Ekker S. C., Young K. E., Lee J. J., Moses K. and Beachy P. A. 1995 The product of hedgehog autoproteolytic cleavage active in local and long-range signalling. Nature 374, 363-366.

Roy A. K., Slimack N. P. and Ganju A. 2011 Idiopathic syringomyelia: retrospective case series, comprehensive review, and update on management. Neurosurg. Focus 31, e15.

Solomon B. D., Mercier S., Vélez J. I., Pineda-Alvarez D. E., Wyllie A., Zhou N. et al. 2010 Analysis of genotype-phenotype correla- tions in human holoprosencephaly. Am. J. Med. Genet. C Semin. Med. Genet. 154, 133-141.

Solomon B. D., Gropman A. and Muenke M. 2011 Holoprosencephaly overview. In GeneReviews (ed. R. A. Pagon, T. D. Bird, C. R. Dolan, K. Stephen and M. P. Adam). University of Washington, Seattle, USA.

Solomon B. D., Bear K. A., Wyllie A., Keaton A. A., Dubourg C., David V. et al. 2012 Genotypic and phenotypic analysis of 396 individuals with mutations in Sonic Hedgehog. J. Med. Genet. 49, 473-479.

Turgut M., Cullu E. and Ulucan H. 2006 Incomplete Currarino triad as an embryological variant. Case report and review of the literature. J. Neurosurg. 105, 6 suppl., 504-507.

Volk A., Karbasiyan M., Semmler A., Todt U., Urbach H., Klockgether T. and Linnebank M. 2007 Adult index patient with Currarino syndrome due to a novel HLXB9 mutation, c.336dupG (p.P113fsX224), presenting with Hirschsprung's disease, cephalgia, and lumbodynia. Birth Defects Res. A Clin. Mol. Teratol. 79, 249-251.

Zen P. R., Riegel M., Rosa R. F., Pinto L. L., Graziadio C., Schwartz I. V. and Paskulin G. A. 2010 Esophageal stenosis in a child presenting a de novo $7 \mathrm{q}$ terminal deletion. Eur. J. Med. Genet. 53, 333-336. 